\title{
Something new? Innovation post COVID-19. A must for tennis
}

\author{
Miguel Crespo ${ }^{\mathrm{a}}$ (1) , \& José Jabaloyes ${ }^{\mathrm{b}}$ (1) \\ ${ }^{a}$ Tennis Development, Integrity and Development Department, International Tennis Federation, London, \\ UK. ${ }^{b}$ Polytechnic University of Valencia, Valencia, Spain.
}

\section{ABSTRACT}

Innovation in sports has been defined as the adoption and use of a novel idea or behaviour by an organisation. The COVID-19 has created an unprecedented situation worldwide. It has affected all aspects of human existence, and sports among them. Using innovation as the main competitive strategy tool, tennis should be positioned as one of the, if not the safest, sport to play in the current climate. This paper aims to reflect on the opportunities for innovation that the pandemic has created for tennis. It presents the different types of tennis organisations and their various approaches to innovation. It suggests possible initiatives that can be implemented by the stakeholders and it discusses alternatives to adapt to the new scenario.
Key words: Management, strategy, COVID-19, innovation. Received: 29 April 2020 Accepted: 29 June 2020 Corresponding author: Miguel Crespo, ITF Bank Lane, Roehampton, London SW5XYZ, Great Britain. Email: Miguel.Crespo@itftennis.com

\section{INTRODUCTION}

Innovation in sports has been defined as the adoption and use of a novel idea or behaviour by an organisation (Winand \& Hoeber, 2017). This idea should be brought into use and be new to the adopter (Winand \& Anagnostopoulos, 2017). It is a very important process because it is associated to the strategic management of the organisation. Furthermore, it is considered crucial for taking advantage and growing in a competitive eco-system by meeting the expectations of the stakeholders, increasing their satisfaction, and adding value to their users through improved quality, efficiency and effectiveness of their experience.

In the sports sector, the impact of innovation can be appreciated by considering the influence of the application of adequate strategies in how sport can be organised, played, consumed and enjoyed in such a way that it is enhanced, refined and improved.

Innovation in sport in general, and in tennis in particular, has been used to improve access, grow user interest, maximise performance, regulate the practice, increase funding, enhance consumer experience, etc. It has been applied to all levels of the game; from grassroots and participation to elite and highperformance (Ringuet-Riot, \& James, 2013). Innovation is closely related to entrepreneurship since both involve change, enable progress, anticipate future trends and foster proactivity (Ratten \& Ferreira, 2017).
A considerable body of research has studied the importance and characteristics of innovation in sport in general (see Tjonndal, 2016 for a review). As per the case of tennis, technology innovations have received most of the attention from the researchers (Kim \& Pennings, 2009; Laudone, Liguori, Muldoon, \& Bendickson, 2015; Luitzen, Bollerman, \& Delheye, 2015; Sheridan, 2006).

The COVID-19 has created an unprecedented situation worldwide. It has affected all aspects of human existence, and sports among them. As IOC President Thomas Bach stated "With the global COVID-19 pandemic, we are all living in much uncertainty. At this point in time, this uncertainty is far from subsiding [...]. This new situation will need all our solidarity, creativity, determination and flexibility. We shall all need to make sacrifices and compromises. Extraordinary circumstances call for extraordinary measures. This situation requires every one of us to do our part, and this applies to all of us, including the IOC" (Bach, 2020).

The tennis community is also facing considerable challenges and risks as our sport is disrupted by Covid-19. Using innovation as the main competitive strategy tool, tennis should be positioned as one of the, if not the safest sport to play in the current climate.

This paper aims to reflect on the opportunities for innovation that the pandemic has created for tennis. It presents the different basic types of tennis organisations and their various approaches to innovation. It suggests possible initiatives that 
can be implemented by the stakeholders and it discusses alternatives to adapt to the new scenario.

\section{TYPES OF TENNIS ORGANISATIONS AND APPROACHES TO INNOVATION}

Two types of tennis organisations can be distinguished in tennis according to the distribution of their income: profit and non-profit. Private companies operating in the tennis sector are usually profit organisations. Federations, associations and clubs are usually non-profit institutions or entities.

Authors such as Newell \& Swan (1995) consider that the importance, need and ability to innovate is equally relevant for both types of organisations due to the gradual increase in professionalisation and commercialisation of the business. However, it has also been indicated that both types of organisations need to implement different approaches to innovation.

Innovations can be driven and implemented following a topdown or a bottom-up approach depending on who is developing the process, at upper level (top) or at local/individual level (bottom) (Winand \& Anagnostopoulos, 2017).

Several types of innovations have been identified in sport (Hipp \& Grupp, 2005; Walker, 2008):

- Technical: linked to the core activity of the organisation. Products, services, projects and technologies. Types:

- New sports products: equipment, devices, technologies.

- New sports services: new acts or processes. training programmes for coaches, players or officials. Subtypes include: total (new services provided to new users), expansionary (existing services provided to new users) and evolutionary (existing services provided to new users).

- Administrative: related to non-sport activities of the organisation. Structural, administrative and managerial practices, aspects, policies, systems or processes. Examples: new registration system for players, new competition structure, etc.

Other authors also identify social, user, organisational and institutional innovations (Tjonndal, 2016).

Service and administrative innovations are more common in tennis non-profit organisations. Four dimensions have been identified which affect their innovation capability (Winand \& Hoeber, 2017):

- Strategic: environment, competitors, market, stakeholders.

- User: expectations and involvement in the process.

- Financial: monetary resources, sponsors, funding institutions.

- Human: staff, volunteers, fans.

\section{SUGGESTIONS ON SPECIFIC INNOVATIONS}

It is therefore crucial to put together the different means, skills and competences available both individually and from the organisations in order to be able to generate new knowledge, to attract new resources, to grow and to differentiate from our competitors (Winand \& Anagnostopoulos, 2017).

Innovation in tennis needs to be introduced in the market as solutions to the existing challenges or needs. The needs analysis and assessment will identify the performance gaps that should be addressed. These ideas or behaviours will assist in changing the way we relate to and enjoy tennis (RinguetRiot \& James, 2013).

Several suggestions to this end include the following (Buttfield \& Polglaze, 2017):

- Change your mindset: the continuously changing scenario makes it impossible for long-term planning. All tennis activities need to be reviewed and, if needed, adjusted to the new realities.

- Adapt your philosophy: whether is your business, coaching or training principles and values, consider the possibility of adapting and refining them to the new situation.

- Be positive towards newness: all involved should show a positive attitude towards innovation by accepting the competitive pressure for performance as a business.

- Identify the needs: understanding your players, the parents, club and board members better and knowing what do you need to implement to adequately fulfil their demands is an extremely relevant phase of this process.

- Inform your audience: people need information on the initiatives that you are going to implement. A clear, direct, honest and timely communication strategy is crucial.

- Make tennis feasible: all those involved need to establish the adequate priorities and appropriate management strategies that will help to make tennis feasible and successful.

- Create a safe environment: this should be the first priority. The health of all participants is the most important. Everyone should follow at 
all times the advice of the World Health Organisation (WHO) and the local authorities.

- Implement cost-saving measures: review budgets in order to decide the most convenient potential adaptations to the organisation of tennis activities.

- Use internal and external sources: involve the organisation's staff but also engage your customers, participants and stakeholders by asking their views.

- Look at partnerships: maybe now it is the right time to join forces with a gym if you own a tennis academy, or with a nearby school if you manage a club, or with another coach or programme if you work on your own. These partnerships may assist in gaining legitimacy and reducing uncertainty.

- $\quad$ Generate a strong competitive position: this has to be done by reducing the barriers of entry to the game. The costs of participating in tennis have to be lowered (i.e. reduce the class fee, offer free racquets, balls, set cheaper court rental depending on certain times of the day, etc.).

- $\quad$ Be sustainable: implement measures (i.e. balls or equipment rental) that will assist in reducing the environmental impact of the activities (i.e. reducing the use of throw-away plastic, introducing waste recycling policies, reducing water use, etc.).

- $\quad$ Think ahead: while looking back may help in the understanding of the causes that brought us to the current situation, at present it may be advisable to implement the new measures and think of possible actions in case the situation arises again.

- Use technology: think of implementing or improving services which are delivered through the use of technology (i.e. social media, mobile devices, wearables, etc.)

- Aim local: due to the travel restrictions, it is advised to start with local activities which do not require players to engage in long trips.

- Empower people: innovation should be driven not by technology, services or products, but by people. Therefore, it is of paramount importance to provide them with the tools to achieve this.

Above all, we should be able to position tennis as one of the preferred options for the return to physical activity. Due to its special characteristics as an individual non-contact sport and to the fact that it respects the social distance, it has to be presented as a safe way of exercising in these circumstances.

As lockdown restrictions are gradually eased in some parts of the world, the identification of clusters of local players to increase localised playing opportunities should be done following the guidelines set by the local relevant authorities.

Even though industry reports indicate that March 2020 sales are down as compared to those of one year ago (TIA, 2020), there are reported examples of large increases in interest to play in many countries and manufacturers have indicated that sales of introduction level rackets and balls between March and June in 2020 are double that of 2019 (Wolken, 2020).

\section{CONCLUSION}

Innovation in tennis should be driven by the principle that we should not just return to the situation we had pre COVID-19, but to a better tennis eco-system that will be able to learn from what happened and to be more adequately prepared for future events whichever they may be.

Everyone that loves our game has the great responsibility to transform the postponement of tennis play caused by the pandemic into an amazing opportunity. During these unprecedented times, the tennis world can use innovation strategies to accept the challenge, to promote, adapt and improve our sport and to celebrate the hope, benefits and enjoyment of tennis play.

\section{REFERENCES}

Bach, T. (2020). IOC President Bach writes to Olympic movement: Olympism and Corona, Olympic News 20 April, Available at: https://www.olympic.org/news/ioc-president-bach-writes-toolympic-movement-olympism-and-corona

Buttfield, A., \& Polglaze, T. (2016). People, not technology, should drive innovation in elite sport. Sensoria: A Journal of Mind, Brain \& Culture, 12(2), 10-12, https://doi.org/10.7790/sa.v12i2.438

Kim, H. E., \& Pennings, J. M. (2009). Innovation and strategic renewal in mature markets: A study of the tennis racket industry. Organization Science, 20(2), 368-383, https://doi.org/10.1287/orsc. 1080.0420

Laudone, R., Liguori, E. W., Muldoon, J., \& Bendickson, J. (2015). Technology brokering in action: revolutionizing the skiing and tennis industries. Journal of Management History, 21 (1), 114-134, https://doi.org/10.1108/JMH-03-2014-0068

Luitzen, J., Bollerman, T., \& Delheye, P. (2015). Playing on the Field of Social and Technical Innovation: The Impact of the Sale of Lawn Tennis Sets in the Netherlands, 1874-1887. The International Journal of the History of Sport, 32(9), 1181-1204, https://doi.org/10.1080/09523367.2015.1071356

Newell, S., and Swan, J. (1995). The diffusion of innovations in sport organizations: An evaluative framework. Journal of Sport Management, 9(3), 317-333, https://doi.org/10.1123/jsm.9.3.317

Ratten, V., \& Ferreira, J. (2017). Entrepreneurship, innovation and sport policy: implications for future research, International Journal of Sport Policy and Politics, 9:4, 575-577, https://doi.org/10.1080/19406940.2017.1380683

Ringuet-Riot, C., \& James, D. A. (2013). Innovating to grow sport: The wider context of innovation in sport. Proceedings of ASTN, 1(1), 40.

Sheridan, H. (2006). Tennis technologies: de-skilling and re-skilling players and the implications for the game. Sport in society, 9(1), 32-50, https://doi.org/10.1080/17430430500355782

Tennis Industry Association (2020). Tennis Retailer COVID-19 Impact Survey. Sports Marketing Surveys, USA, available at: https://www.usta.com/content/dam/usta/2020pdfs/2020\%20Tennis\%20COVID\%20Impact\%20Survey\%20Report SummaryEdit.pdf

Tjonndal, A. (2016). Sport, innovation and strategic management: A 
systematic literature review. Brazilian Business Review, 13(Special Ed), 38-56, https://doi.org/10.15728/edicaoesp.2016.3

Winand, M. \& Anagnostopoulos, C. (2017). Get ready to innovate! Staff's disposition to implement service innovation in non-profit sport organisations. International Journal of Sport Policy and Politics. https://doi.org/10.1080/19406940.2017.1308418

Winand, M. \& Hoeber, L. (2017). Innovation capability in non-profit sport organisations. In: V., Ratten \& J., Ferreira (Eds.), Sport Entrepreneurship and Innovation, London: Routledge, pp. 13-30.

Wolken, D. (2020). Working out from home: How tennis can be played safely amid coronavirus pandemic in USA Today, 3 April, available at: https://eu.usatoday.com/story/sports/2020/04/30/coronaviruswhy-tennis-might-perfect-sport-social-distancing/3052759001/

RECOMMENDED ITF TENNIS ACADEMY CONTENT (CLICK BELOW)

\section{ITF Academy}

Copyright (c) 2020 Miguel Crespoa \& José Jabaloyes

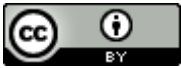

This text is under a Creative Commons BY 4.0 license

You are free to Share - copy and redistribute the material in any medium or format - and Adapt the content - remix, transform, and build upon the material for any purpose, even commercially under the following terms:

Attribution: You must give appropriate credit, provide a link to the license, and indicate if changes were made. You may do so in any reasonable manner, but not in any way that suggests the licensor endorses you or your use.

CCBY4.0 license terms summary $\quad$ CCBY4.0license terms 